\title{
Stage III Urethral Cancer AJCC v7
}

National Cancer Institute

\section{Source}

National Cancer Institute. Stage III Urethral Cancer A/CC v7. NCI Thesaurus. Code C6199.

Stage III includes: (T1, N1, M0); (T2, N1, M0); (T3, N0, M0), (T3, N1, M0). T1: Tumor invades subepithelial connective tissue. T2: T umor invades any of the following: corpus spongiosum, prostate, periurethral muscle. T3: Tumor invades any of the following: corpus cavernosum, beyond prostatic capsule, anterior vagina, bladder neck. N1: Metastasis in a single lymph node $2 \mathrm{~cm}$ or less in greatest dimension. N0: No regional lymph node metastasis. M0: No distant metastasis. (AJCC 7th ed.) 